\title{
Women's experiences of medical miss-diagnosis: How does gender matter in healthcare settings?
}

\author{
JESSICA THOMPSON and DENISE BLAKE
}

\begin{abstract}
Medical misdiagnosis for women continues to be a significant problem, leading to disparate health outcomes. To understand how women make sense of experiences of medical misdiagnosis, eight women from Aotearoa/ New Zealand were interviewed about misdiagnosis of conditions that equally affect female and male bodies. This work was guided by feminist principles and used narrative analysis to develop the following three themes: (1) Contradictory dialogues: doctor as expert or not? (2) Self-advocacy in the misdiagnosis experience; and (3) Not taken seriously in healthcare settings: it's all in your head. Supported by previous work, our findings assert that women are treated poorly in healthcare settings with detrimental outcomes for them and their wider community. Reasons for this include female bodies being excluded from medical research, so that little is known about how illnesses present in female bodies, or how they affect women. Problematically, knowledge founded on male bodies is used to diagnose conditions in women. These biases perpetuate gender stereotypes and preconceived beliefs about women. Unexplained symptoms are considered 'made up' or are blamed on women's mental wellbeing. Women are therefore not always considered credible symptom reporters and may be dismissed and ignored by healthcare professionals.
\end{abstract}

Keywords

Misdiagnosis, diagnosis, gender, women, feminist, healthcare, narrative research, androcentric

\section{Why misdiagnosis matters}

Misdiagnosis for women is an increasingly significant health and social problem. Delays in diagnosis can produce self-doubt, psychological distress, social isolation, family strain, increased physical discomfort and treatment-seeking delays, all resulting in heavy illness burdens and potentially death (Berg Gundersen et al., 2016; Waldron et al., 2012; WehbeAlamah et al., 2012). Some women are unable to cope effectively with their illness when they do not have an adequate explanation for their physical symptoms (Levin et al., 2003; Waldron et al., 2012). Research in the United States shows the rates of misdiagnosis (26\%) are higher than those of surgical accident (25\%) (Neale et al., 2011; Pelaccia et al., 2020). Studies also show that women are misdiagnosed at much higher rates than men. Women in the United Kingdom, Brazil, Germany and New Zealand are 30-75 percent more likely to be misdiagnosed for illnesses that equally affect women and men (Newman-Toker et al., 2014; University of Leeds, 2016; Women's Health Action, 2020), while female-specific illnesses, such as endometriosis, take an average of seven years to be successfully diagnosed (Arruda et al., 2003). These findings are troubling and demonstrate problematic misdiagnosis rates, leading to disparate health outcomes for women.

Diagnosis is a valuable tool and offers many functions, including explaining illness, identifying appropriate treatments and predicting outcomes (Gerolamo et al., 2018; Jutel, 2019). A diagnostic error, or 'mis-diagnosis', can therefore be considered as a failure to 
detect disease (Pelaccia et al., 2020) and occurs when a patient is ejected from a healthcare setting without any diagnosis, or is given a diagnosis which is later proven to be incorrect (as evidenced by failure of appropriate treatment). Increased research into misdiagnosis for women will contribute towards more equitable and socially just medical practices that ensure women are included and receive the medical attention they deserve. We begin this exploration by presenting general background information regarding the socio-political conditions which produce androcentric healthcare systems that treat women and their bodies as problematic, and how these matter to (mis)diagnosis.

\section{Medicine and how it sees women and female bodies}

While we recognise that cultural and social contexts have particular effects and are specific to the location of healthcare systems, biomedical healthcare generally reflects an androcentric bias inherent in western societies, including Aotearoa/New Zealand (Munch, 2004; Verdonk et al., 2009). It has long been recognised that within these androcentric healthcare systems, medical knowledge is derived from research conducted on male bodies and generalised to female bodies, which in turn (re)positions the female body as pathological to a male norm (Marcum, 2015; Munch, 2004; Verdonk et al., 2009). Both women and men experience a range of similar health conditions and illnesses (e.g. heart disease), however female bodies continue to be underrepresented in, or entirely excluded, from clinical trials, so that little is known about how certain diseases affect women's material condition specifically (Adams et al., 2008; Davidson et al., 2012; Women's Health Action, 2020; Worrall-Carter et al., 2011). The materiality of female and male bodies differs hormonally, genetically and physiologically. Each has varying presentations and severities of illnesses and symptoms, as well as different responsiveness to 'standard' tests and treatments (Ballantyne \& Rogers, 2011; Celik et al., 2011; Wienclaw, 2013).

When the female body is assumed to be different, and those differences are exaggerated in relation to a male body, an alpha bias occurs and both sexes are presupposed to be treated differently. A beta bias occurs when difference is assumed to not exist or is minimised, and female and male bodies are erroneously treated equally (Alspach, 2012; Hare-Mustin \& Marecek, 1998; Saletti-Cuesta et al., 2016). Smirthwaite and Swahnberg (2016) describe these alpha and beta biases in relation to healthcare and gender as (respectively) Type A: exaggeration or construction of difference between female and male bodies in ways that compromise health and/or cause inequity in care; and Type B: the absence of difference between female and male bodies while making one sex (typically male) the standard for both.

Women's exclusion from health research also produces biases more generally and influences how female bodies are treated in healthcare settings. Biases reinforce gender stereotypes and preconceived beliefs about women (and men), as well as about certain conditions and illnesses; these stereotypes and beliefs are not contested by androcentric empirical research on women and female bodies. Such biases work to obfuscate the ability to observe and process critical clinical information (Marcum, 2015). In effect, healthcare professionals may perceive a stereotypical version of a patient, facilitating prejudice, which leads to misdiagnosis (FitzGerald \& Hurst, 2017).

Moreover, as well as negating women and female bodies, prejudices are enacted and lead to negative treatment by healthcare professionals and misdiagnosis (McSweeney et al., 2005). In their research in the United States, McSweeney et al. (2005) found that that some healthcare professionals considered women patients to be 'time wasters'; they dismissed some symptoms as 'irrelevant' and treated the women patronisingly during their consultations. Waldron 
et al. (2012) in the United Kingdom and Wehbe-Alamah et al. (2012) in the United States similarly found that women who have experienced misdiagnosis report being dissatisfied with medical explanations about their symptoms. Some of the women in these studies were told they were 'over exaggerating' or that their symptoms were 'all in your head'. These forms of condescension imply women are malingerers who create psychosomatic symptoms and work towards fuelling discourses of women as attention seekers or hysterical hypochondriacs.

Further research has identified that women are frequently dismissed from healthcare settings without appropriate tests being conducted, leading to failures in helpful and accurate diagnosis. For example, in the United Kingdom and Spain, spirometry testing for Chronic Obstructive Pulmonary Disorder is utilised more frequently for men than women, despite the proven effectiveness of this test for both genders (Chapman et al., 2001; Delgado et al., 2016). When attention is paid to female bodies in medical research, it focuses on a 'bikini model' of health, as described by Wenger (2004), which centres health on female reproductive systems (menstruation, pregnancy, childbirth, menopause) (also Ballantyne \& Rogers, 2011; Verdonk et al., 2009). This narrow conceptualisation produces huge gaps in medical knowledge, and also contributes to disparate health outcomes (Chen \& Standing, 2007; Payne \& Doyal, 2010; Sanfey, 2005). Some authors argue that such differential health outcomes are the result of patient behaviour, implying that medical misdiagnosis arises from women's inadequacies, because women experience non-normative symptoms, fail to report relevant symptoms and describe symptoms vaguely, making it difficult for a clinician to diagnose their condition correctly (see Alspach, 2012; Saletti-Cuesta et al., 2016). However, if women experience symptoms in ways that are not considered 'standard' for an illness, then it should be an opportunity to apply more rigorous medical knowledge and diagnostic skills to identify the varying symptoms experienced, instead of producing biases (A or B) and misdiagnoses for women because their symptoms do not align with men's symptoms (Adams et al., 2008; Koyama et al., 2018; Ross \& Lypson, 2014).

There is limited research focused specifically on the outcomes of medical misdiagnoses for female bodies and women in Aotearoa/New Zealand. Work by Jutel (2019) acknowledges that diagnosis is a social tool used to explain illness, identify treatment, predict outcomes, allocate resources and strengthen powerful relationship structures between patients and healthcare professionals. The New Zealand government aims to address health inequalities for women (Ministry of Health, 2002), however, their focus is on health that is specific to women and female bodies, such as cervical cancer screening, pregnancy care and breast cancer screening and treatment (Healthed, 2011). The Women's Health Action also addresses this form of 'bikini' health, but does include information about heart attacks among women, including discussion about women being excluded from research about heart disease and heart attacks, differing symptoms of heart disease and heart attacks between female and male bodies, and why sex and gender are important considerations in health and healthcare (Women's Health Action, 2020).

To work towards remedying these health injustices, this current research project aims to shed light on women's experiences of misdiagnosis and how women who have been misdiagnosed make sense of their experiences. It also seeks to give women the chance to share narratives around misdiagnosis and have their voices heard, because the implications of misdiagnosis are often overlooked or ignored by health professionals and researchers alike.

\section{Methodology}

Our research is located firmly in a feminist paradigm. In this way, it is overtly political, and challenges broader social, economic and cultural contexts affecting women's lives (Fish, 2009; 
Ussher, 2004). This research practice is acknowledged as a (co)production of knowledge (Akman et al., 2001). We worked collaboratively with participants through conversational interviews and provided the opportunity for the participants to amend transcripts and follow up with any additional thoughts or responses. We also recognise that our roles as researchers influenced all aspects of the research project, particularly that of the lead researcher who had her own experience with misdiagnosis. The project was reviewed and approved by the Massey University Human Ethics Committee: Southern A, Application SOA 18/32.

We drew on a narrative methodology for the project, because we understand that experiences, such as accessing healthcare, act as mirrors for social realities (Rickard, 2015; Squire et al., 2013). Narratives enable sense-making by providing spaces for sharing stories, along with a sense of closure and validation, particularly when narratives represent troubling experiences (Akman et al., 2001; Latz, 1994; Rickard, 2015). Sense-making can be seen as the interplay between inner dialogue and social contexts, where sense emerges over time through multiple interactions and recounting of experiences, either alone or with others, enabling insight into an experience (Dowding et al., 2016; Harrington, 2017; Wright et al., 2004). Narratives are thus a valuable way to organise human experience and social relationships.

Narratives can be analysed in many ways, however we focused on meaning and social structure, rather than plot or language (Kim, 2016; Rickard, 2015; Squire et al., 2013). As we interpreted the narratives, no specific theoretical underpinning was adhered to (Smythe, 2012). Instead, the women's voices and their narratives were privileged, and a descriptive and interpretative analysis was used to look for patterns in the narratives that would inform narrative themes (Kim, 2016; Walsh et al., 2015).

Participants were recruited through public advertising and subsequent snowballing. In total, eight women participated, all of whom were living in Aotearoa/New Zealand and who had experienced misdiagnosis with a health condition that was non-gender specific; that is, they were all illnesses or conditions that are equally likely to affect women and men. Their misdiagnoses included not receiving a diagnosis, or receiving a diagnosis that did not fit symptoms and that was later proven to be incorrect by failure of treatment or by success of alternate treatment (including diagnoses of mental health issues).

The participants' illnesses varied from acute to chronic, with several women having multiple health issues for which they had also experienced misdiagnosis. Some of these diagnoses were disputed by the women and are noted as such. Table 1 describes participants' 'official diagnosis', the time it took for the healthcare system to reach that diagnosis, and the seriousness of the illness or condition if it remains untreated. All of the women described their illness or condition as having a significant impact on their lives, which also affected their families and whānau.

Table 1. Diagnostic Information for Participants

\begin{tabular}{|l|l|l|l|}
\hline Participant & $\begin{array}{l}\text { Time to diagnosis in } \\
\text { healthcare system }\end{array}$ & 'Official' biomedical diagnosis & Effects of condition \\
\hline Amiria & Three years & Trigeminal neuralgia & Significantly debilitating \\
\hline Cara & A few days & Sudden sensorineural hearing loss & Permanent hearing loss \\
\hline Piper & Fifteen years & Chemical sensitivity exposure (disputed) & Significantly debilitating \\
\hline Zoe & Two weeks & Hypokalaemia & Death (heart arrhythmia) \\
\hline Hannah & One year & Chronic fatigue syndrome & Significantly debilitating \\
\hline Nicole & Twenty-one years & Ehlers Danlos syndrome & Significantly debilitating \\
\hline Amy & One year & Motor neuron disease (disputed) & Death \\
\hline Bryony & Two months & Breast cancer & Death \\
\hline
\end{tabular}


Of the eight participants, one identified as Māori, one as mixed-American, and six as New Zealand European or Pākehā. Participant's ages ranged from 26-57 years old. One-on-one, semi-structured interviews were conducted, following an interview guide. Pseudonyms were given to the women (and these are used throughout the article), and the final diagnoses the women received are included to represent the range of illnesses and provide context.

\section{The narratives and finding meaning}

We are focusing in this article on the three main narrative themes that emerged from our interpretation of the women's stories about their misdiagnosis experiences: (1) Contradictory dialogues: doctor as expert or not? (2) Self-advocacy in the misdiagnosis experience; and (3) Not taken seriously in healthcare settings: it's all in your head. While the third narrative stands on its own, aspects of it were interwoven throughout the other two themes, representing the complexity and interconnectedness of social meaning and relationships.

\section{Contradictory dialogues: Doctor as expert or not?}

Within the participants' misdiagnosis experiences, contradictory dialogues highlighted how women position their healthcare professionals as experts who nevertheless lack adequate expert knowledge. This contradiction represents how opposing ideas can operate simultaneously. In western cultures that value empirical rationality (as in medicine) and a 'singular' truth, contradictions can be troubling (Colyar, 2012). Even so, they allow the exploration of two paths, both of which provide innovative insights into experiences and processes that are troublesome and need to be reviewed in some way (Hagel et al., 2013; Squire et al., 2013).

Five of the women stated that they believed their healthcare professionals had extensive training and experience with illness. This expertise initially convinced participants that they were given an accurate diagnosis and appropriate treatment. For instance, Zoe and Amiria accepted an initial diagnosis from their healthcare professionals:

I figure she knows what she's doing. She didn't seem worried about it, so I was like ok. I'm not a doctor, I don't know enough about this. (Zoe, hypokalaemia)

You assume as a human being who doesn't know as much as they do, that they know what's best because they're the professionals. So, you go along with what they say, and you listen to them because they're the professionals. (Amiria, trigeminal neuralgia)

The women's belief about the 'doctor as expert' was supported by their assumption that they themselves 'did not know' because they were not healthcare professionals. Both participants position themselves as subordinate because they knew less about their health than a healthcare professional. Healthcare professionals are elevated to a higher status due to their assumed knowledge and skills in illness diagnosis and treatment (Ceplak \& Hlebec, 2012; Jutel, 2019). These women's words illustrate how they initially trusted in their healthcare professionals' decision-making around symptom clusters and management, believing they were acting with competency and reliability (Ceplak \& Hlebec, 2012; Jutel, 2019).

Conversely, when the women in this study were asked specifically why they thought they had been misdiagnosed, six responded that it was due to their healthcare professional lacking knowledge about their illnesses, thereby demonstrating a contradiction with the 'doctor as expert' discourse. It can be surmised from the participants experiences that, while a healthcare professional is considered knowledgeable, they are also not knowledgeable enough. The following two excerpts highlight how this lack of knowledge led to misdiagnosis: 
They put me in hospital for a good four or five years and just dosed me up on steroids cos they had no idea what was going on. (Nicole, Ehlers Danlos syndrome)

All I kept getting was: 'it's a medical mystery. We're not sure why it happens.' Great! That's fine. But that's the one thing that's been consistent: GPs (General Practitioners) don't seem to be educated at all on this condition. (Cara, sudden sensorineural hearing loss)

Nicole and Cara were diagnosed with conditions that were rare or unknown, which in a way could have served to absolve the healthcare professionals from an ethics of care, while offering a reason for their knowledge gap. Two other participants also narrated how they were convinced that their illnesses were rare and unknown within the medical community. Like Nicole and Cara, having an uncommon health condition also served as a rationale for why their doctor as the expert was unable to make a correct diagnosis.

When asked, most of the participants did not know why their healthcare professionals were unable to definitively identify their illness. When a healthcare professional lacks knowledge, a regular outcome is either no treatment, delayed treatment or referrals to specialists, who are often the gatekeepers to additional treatment (Briones-Vozmediano, 2017; Waldron et al., 2012). For two participants, unsolvable conditions led to years of hospitalisations and undergoing serious drug treatments. Not having an explanation for health conditions can also produce anxiety, limit coping and throw doubt on the seriousness of the symptom reporter; this is confirmed by Levin et al. (2003) and Waldron et al. (2012) who (respectively) investigated women's experiences of misdiagnosed Systemic Lupus Erythematosus in Israel and Multiple Sclerosis in the United States.

The health conditions experienced by the women in this study were not specific to female bodies, which coheres with the design of this project, yet half of the conditions the women described are more common in female than male bodies, and, as such, they may have been subject to less medical interest and research (see for example Briones-Vozmediano's work on fibromyalgia, 2017). This could explain why healthcare professionals claimed the illnesses experienced were 'rare' or 'unknown'.

Traditionally, within western societies that value knowledge and power (including Aotearoa/ New Zealand), healthcare professionals are positioned as experts and therefore command respect, while patients are passive consumers of their medical 'gaze' (Balcioglu, 2012). As demonstrated by the women in this study, patients in these medical systems are socialised to accept medical decisions and not challenge them (Ceplak \& Hlebec, 2012; Hagan et al., 2017; Joseph-Williams et al., 2014; Jutel, 2019). In particular, women can be confronted by power dynamics in doctor-patient interactions and face barriers to treatment from medical experts who seemingly refuse to listen to women who challenge treatment recommendations based on knowing their own bodies (Joseph-Williams et al., 2014; Katz et al., 2008). As Jutel and Dew (2015) note, diagnosis is a social exchange, and the authority to diagnose lies with the role socially assigned to healthcare professionals. To contest power dynamics and social roles, Colyar (2012) suggests an approach that allows for a valuable dialogic, where more than one dialogue is heard, and respected. This type of dialogic will enable the complexity of social and material lives to remain intact, rather than being reduced to a mere description. For example, listening to women's experiences and expertise about their bodies and considering that information in the diagnosis process, rather than dismissing it as ambiguous or irrelevant information, would create a space that values both parties' knowledge (Teunissen et al., 2016). Such an approach is incredibly important to women being heard and considered during consultations with healthcare professionals.

Unfortunately, however, valuable dialogue is rare and not widely practiced as a way of 
understanding two parties in social contexts, particularly in western societies (Colyar, 2012). As a consequence, women are often dismissed from healthcare settings despite speaking up about their symptoms. This in turn propels them to advocate for themselves, when possible, and fight for diagnosis and treatment. This self-advocacy is discussed in the next section.

\section{Self-advocacy in the misdiagnosis experience}

Participants in this study spoke frequently, but at times implicitly, about self-advocacy in their misdiagnosis narratives. Self-advocacy can be conceptualised as a person seeking to get their needs met when facing a challenge (Hagan et al., 2017). In a health context, this can include making informed decisions about healthcare treatment, navigating healthcare systems, working collaboratively, and communicating effectively with healthcare professionals. A range of research (see, for example, Ruggiano et al., 2014, Valenti, 2011, Wiltshire et al., 2006) recognises that when successful, self-advocacy produces better health outcomes and improved interactions between patients and healthcare professionals.

Every woman's narrative in this study represented her self-advocacy. This ranged from the women researching their conditions, asking for tests, approaching specialists themselves (particularly as symptoms persisted or worsened), designing treatments and other actions associated with fighting for access to healthcare.

Five of the women discussed doing their own research into symptoms and treatments. These women were quick to point out that this was through valid research practices, drawing on reputable sources rather than the derided 'Dr Google' or 'Web MD' culture (Lyons \& Chamberlain, 2013). We can assume that having credible knowledge was important to the women who had been positioned as inauthentic malingers, and also resonates with our social imperative of valuing 'expert knowledge'. The women explained they did research to gain information, answer questions and push for further treatment after being constantly ignored or dismissed in the healthcare system. However, as the quotes below show, when participants presented their research findings to their healthcare professionals, they were met with disbelief, cynicism or dismissal:

I said to her that every symptom I have and everything I've researched and studied, and then she gave me the, 'and what, Googled?' (Amiria, trigeminal neuralgia)

A lot of this stuff I was reading, that I got from uptodate.com which is a medical site, and I would mention that to the specialist but they're not really keen to discuss it with you. I'm told things like 'oh you read too much', 'you shouldn't believe everything you read on the internet', all that kind of stuff. (Amy, motor neuron disease - disputed)

To be dismissed as naïve or gullible served to potentially silence and disempower these women and limit their agency over their own self-advocacy and health. The 'doctor as expert' discourse is also clearly demarcated in the following example. After suffering with extreme pain for approximately five years, Amiria conducted extensive research and self-diagnosed her condition. However, it took a further three months to convince her healthcare team to take her findings seriously. As Amiria recounts, this resulted in further frustration, extreme distress and continuing delays in receiving treatment:

Diagnosis was based not upon them giving me one, but me telling them what I had. I told them I think I've got TN [trigeminal neuralgia] and then the nurse was just like, her face was like, 'why do you think that?' In a rude sarcastic way, that's exactly how she answered me. They gave me some stuff to put me to sleep so I would have a remission period ... and it didn't work. And that was when she finally said, 'I think we should get someone else'. They then got a guy in and he said, 'Oh it sounds like trigeminal neuralgia'. And I was like, I’ve been trying to tell you guys this for three months! (Amiria, trigeminal neuralgia) 
That the healthcare professional discounted Amiria's self-diagnosis is problematic beyond the experience of Amiria or the other women in this study. Without self-advocacy, that is, pushing to get their needs met, the women in this study would not have gained correct diagnoses or appropriate treatments, and subsequently, relief from symptoms. Women outside of this study might not have the wherewithal to advocate for themselves and contest medical experts due to social power and positioning. While Amiria had a voice, her situation demonstrates how difficult it is for women to self-advocate in the face of healthcare professionals who are sceptical, who do not take women patients seriously and who traditionally silence and ignore women. This is discussed more fully in the next theme that covers women having little credence in healthcare.

\section{Not taken seriously in healthcare systems: It's all in your head}

This theme focuses on how women are perceived in healthcare settings. The literature (see, for example, Lorentzen, 2008; Maserejian et al., 2009; Verdonk et al., 2009) reflects that women are often positioned as mentally unwell rather than physically unwell, which also contributes to them not being taken seriously as symptom reporters. This in turn poses another barrier to accurate diagnosis and treatment and is, unfortunately, incredibly common in women's experiences in healthcare settings, particularly around misdiagnosis (Alspach, 2012; Lorentzen, 2008). The implication is that the symptoms women report are not related to a physical condition, but are 'made up', or the result of a mental health condition. Historically, chronic conditions with inexplicable symptoms that affect more women than men fell under the category of 'hysteria' and were not taken seriously by the medical community or considered legitimate medical conditions. Examples of these include fibromyalgia, chronic fatigue syndrome and multiple sclerosis (Katz et al., 2008; Ussher, 2013). This type of situation was mentioned by Bryony:

It's always women who are put into categories of things like ME [myalgia encephalitis], which basically just means 'we have no idea what's wrong with you so we're going to label you with this meaningless term and stick you in a box and ignore you.' (Bryony, breast cancer)

Bryony's comment reflects the experiences of many of the other participants who recounted that their symptoms seemingly had no explanation, and therefore they were not taken seriously as an ill person. For some of the women in this study, healthcare professionals suggested that symptoms were the result of anxiety or depression. The women experienced this as incredibly frustrating. They described the need to assert to their healthcare professional that they had the ability to recognise symptoms of anxiety and depression as being different to their current physical symptoms. Piper provides an apt example of this below:

I said, 'Look, I've had a panic attack before, I know what that feels like. This is not it'. I said, 'I've been depressed, I know what depressed feels like, I'm not talking about that'. (Piper, chemical sensitivity - disputed)

To be clear, the distress described by the women in this study was the result of their misdiagnosis - not being taken seriously, or having symptoms worsen (either through mistreatment or through no treatment). The distress they described was not an outcome of their initial symptoms or the consultations. During their interviews, the women noted how they would present calmly to their healthcare professionals. Zoe's narrative provides an exemplar of her GP's response at a follow-up meeting (after they had misdiagnosed Zoe's illness):

[The GP said] I'm so, so sorry. I did not realise how sick you were. And your mannerism, you're just very staunch whenever you talk to me as a GP. (Zoe, hyperkalaemia) 
Zoe's enactment of 'staunchness' can be interpreted as the management of any sick identity, so as not be seen as hysterical, but rather as a credible symptom reporter (Katz et al., 2008; Ussher, 2013). Other participants recounted speaking in a 'straightforward' manner with healthcare professionals, seemingly with the intent of justifying their actions and being taken seriously.

Briones-Vozmediano's (2017) and Maserejian et al.'s (2009) research confirms that often the first diagnosis a woman receives is that of a mental health condition, such as depression. Once (mis)diagnosed in this way, she may find it more difficult to be taken seriously as a patient suffering physical symptoms (Donskoy, 2015; Ussher, 2013). Additionally, once a psychological diagnosis has been reached, or any other diagnosis, the process of diagnosing ceases altogether and other potential diagnoses are not considered (Britto, 2018; Graber et al., 2005). Yet to not be taken seriously as a symptom reporter, or to be told that symptoms are made up or 'all in your head', is detrimental to women's health and ultimately, their wider communities.

Quick to point out that they were not 'crazy' or frequent users of healthcare and that they had legitimate physical symptoms, the women in this study demonstrated awareness of social perceptions of women as hypochondriacs or attention seekers who visit healthcare settings at the slightest symptom (see Nicolson, 2004, whose work on biological politics challenges and contests 'man'-made science and understanding of women's bodies and health care, particularly how women are seen in healthcare settings). It also reflects an androcentric-western healthcare system, where women are ousted from healthcare settings without appropriate medical tests. To challenge mental health judgements, some of the women reported that they managed the frequency of their healthcare usage to increase their credibility with healthcare professionals. For example:

I never was a hypochondriac. I'd always avoid going to the doctor. I wasn't that sort of person. (Amy, motor neuron disease - disputed)

I hardly go to the doc - I don't like going to the doctor, I don't make a habit of going to the doctor. In fact, I would only go when I have these (episodes). They don't see me from one, two-year, three-year slot to the next. I'm not a regular caller. (Piper, chemical sensitivity - disputed)

Being misdiagnosed meant that Piper did not seek help from a doctor, and she would have two to three-year gaps between visits. Nicole, like Piper, disliked visiting doctors as the interactions were distressing. Nicole was specifically told that symptoms were 'all in your head' and not legitimate. This worked to erode her trust in the healthcare system:

There's nothing to see, there's nothing to fix, so, what are you here for? We can't help you. Go home, it's all in your head. It was pretty severe and serious but at that point I had doctors telling me: 'your mother's making it up and putting it in your head'. Or, 'we can't find out what's wrong with you so there's nothing wrong with you'. (Nicole, Ehlers Danlos syndrome)

These types of attitudes and treatment by healthcare professionals can produce a sense of wariness for women trying to navigate healthcare systems and thus can provoke health avoidance actions. Three women in this study mentioned using alternative treatments, refusing appointments with specialists and holding off visiting a healthcare professional until symptoms were persistently intolerable. As reflected in the literature (see, for example, Berg Gundersen et al., 2016), this response is alarming and diminishes well-being. Regular health checks are important at certain times in people's lives (for example, monitoring for hypertension, which is a precursor to cardiovascular diseases; Department of Health and Social Care, 2013).

Western medicine's attitude to women was articulated by one participant, who summarised why healthcare practices resulted in poorer outcomes for women. Bryony stated: 
I think it's the attitude to female biology. The fact that there isn't the research on women's health that there is on men's. That it's assumed that we are, or being hysterical and I don't - I think that we're seen as: there's people and then there's women and we're the abnormal, we're the difficult and you can't worry about people like that in the same way as you worry about, you know, real people. (Bryony, breast cancer)

Bryony's narrative epitomises other research on gender and health, in that the female body is assumed to be either different or similar to the male body. These biases (re)produce women (who are more than a body) as lesser to the male norm. Bias and poor attitudes towards women operate implicitly in healthcare systems, but by drawing attention to health injustice we may render them ineffective (Beaumont, 2016; Chapman et al., 2013; FitzGerald \& Hurst, 2017). Throughout this analysis, we have highlighted how women described experiences of being treated rudely, not being taken seriously and being unable to gain fit-for-purpose diagnoses that would have provided effective treatment of their symptoms.

\section{In closing}

Three narrative themes were represented in this research report. Each theme came from the women's stories about their misdiagnosis experience, namely: contradictory dialogue around 'doctors as experts' who also have inadequate knowledge - particularly around conditions that affect female bodies more frequently and have little research conducted on them; how selfadvocacy played a role in women's interactions with healthcare professionals - though not always successfully; and how women are seen in healthcare settings as having psychological symptoms rather than physical symptoms.

An androcentric western healthcare system that values and privileges male bodies impacts how women get to experience health. Excluding women from necessary health research is a human rights issue. Women can be positioned, at times, as unreliable symptom reporters, even about their own bodies, and as such, they are silenced and ignored by a healthcare system that privileges men and dismisses women.

Some of the participants in this project queried whether an increased number of women in medicine has changed or could change attitudes towards, and treatment of, women patients in healthcare. However, as noted by Risberg et al. (2011), women doctors acquire knowledge and social practices within a problematic androcentric healthcare system that continues to privilege male over female, and likely influences their thinking and attitudes towards women/female patients. This was evidenced in the participants' narratives, when they described scenarios where women healthcare professionals were rude or dismissive. More women in medical training facilities would not necessarily change medical pedagogy, without medical training programmes being re-written in a way that considered how androcentric practices and bias influence the way women are treated. Including more women in training facilities also fails to overcome the exclusion of women/female bodies from healthcare research and textbooks. Countering this exclusion is so desperately needed if we are to better understand women and female bodies. Additionally, gender as a topic needs to be embedded in the overall curriculum of healthcare training, rather than simply included within elective courses about gender or women (Bleakley, 2013; Hamberg et al., 2002; Risberg et al., 2011).

Women who have fewer resources, such as those living in underprivileged or disadvantaged circumstances, will undoubtedly face more barriers to gaining a correct diagnosis, as their socioeconomic status (SES) intersects with their gender (Parker et al., 2017; Wiklund et al., 2016). This could affect their ability to successfully self-advocate, or repeatedly visit a healthcare professional, or seek alternative or specialist treatment due to limited time, money and resources. Similarly, those affected by structural violence, where a 
social structure or institution creates harm by preventing their ability to meet their basic needs (Weigert, 2008), are harmed by practices that constrain their agency on the basis of their ethnicity or sexuality (Farmer, 2004). Being a member of a marginalised community intersects with gender and SES, and affects a person's ability to contest unsatisfactory treatment.

This study is a product of the time and place in which it is situated (Smirthwaite \& Swahnberg, 2016). A predominantly white sample was recruited, reflecting the larger populational composition of Aotearoa/New Zealand, and the dominance of white voices in research (Holmes, 2016). As such, we recommend engaging with other ethnic groups with regard to misdiagnosis in Aotearoa/New Zealand, particularly Māori and Pasifika communities, as it could provide further insights into the intersections of ethnicity with misdiagnosis and treatment in healthcare settings. Although a plethora of research attests to the poorer outcomes for Māori health (see, for example, Reid et al., 2019; Houkamau et al., 2017), which is attributed to colonisation, racism and bias, it would be invaluable to shine a torch on misdiagnosis for Māori women specifically. The Ministry of Health Manatū Hauora is committed to reducing inequalities in health for New Zealanders, focusing on structural elements that are the root causes (Ministry of Health, 2002), and this current research will help to highlight a significant health injustice.

There is little research that explores the experiences of healthcare professionals with regard to misdiagnosing patients. While it was not the intention of this work to include healthcare professionals' narratives, understanding how these professionals frame their experiences would offer further insight into the misdiagnosis phenomenon, particularly for those who are unaware they have misdiagnosed, as they may not see the patient again. Including the healthcare professionals' voices will offer a holistic sense-making option and open up a valuable dialogue between patient and healthcare professional that could lead to insight and understanding around the misdiagnosis phenomenon (Colyar, 2012; Latz, 1994). We also acknowledge that the healthcare system is under-resourced, and healthcare professionals are often overworked, both of which create difficult environments in which to work.

Misdiagnosis and the poor healthcare experiences for women in healthcare settings are still happening, despite attention first being drawn to this issue over 30 years ago (Munch, 2004). Misdiagnosis has significant health implications for women, their families and the wider community. As such, we must continue to work towards addressing this serious social injustice for the health and wellbeing of all. Failure to continue to do so has potentially fatal consequences.

JESSICA THOMPSON is a member of the School of Psychology at Massey University. Her research is situated in critical health psychology, concerning women and bias in healthcare settings. She is currently involved in projects concerning accessing healthcare during the COVID-19 lockdown. Jessica values collaborative feminist research as a way to challenge embedded injustices around gender.

DENISE BLAKE is a member of the School of Psychology at Massey University. She teaches critical health psychology and emergency management courses. Her research concerns issues of social justice, including identity, welfare, health and disaster management. She is currently involved in projects that explore sex workers' rights and homelessness in disaster contexts, as well as Māori experiences of adoption and whāngai. Denise values using collaborative and community embedded research approaches to complex social issues. 


\section{References}

Adams, A., Buckingham, C. D., Lindenmeyer, A., McKinlay, J. B., Link, C., Marceau, L., \& Arber, S. (2008). The influence of patient and doctor gender on diagnosing coronary heart disease. Sociology of Health \& Illness, 30(1), 1-18. https://www.ncbi.nlm.nih.gov/pubmed/18254830.

Akman, D., Toner, B., Stuckless, N., Ali, A., Emmott, S., \& Downie, F. (2001). Feminist issues in research methodology: The development of a cognitive scale. Feminism \& Psychology, 11(2), 209-227.

Alspach, J. G. (2012). Is there gender bias in critical care? Critical Care Nurse, 32(6), 8-14. https://www.ncbi. nlm.nih.gov/pubmed/23203950.

Arruda, M., Petta, C., Abrao, M., \& Benetti-Pinto, C. (2003). Time elapsed from onset of symptoms to diagnosis of endometriosis in a cohort study of Brazilian women. Human Reproduction, 18(4), 756-759.

Balcioglu, Z. (2012). The medical gaze between the doctor, the patient, and the state. https://www.e-ir. info/2012/10/11/the-medical-gaze-between-the-doctor-the-patient-and-the-state/.

Ballantyne, A. J., \& Rogers, W. A. (2011). Sex bias in studies selected for clinical guidelines. Journal of Women's Health, 20(9), 1297-1306. https://www.ncbi.nlm.nih.gov/pubmed/21823920.

Beaumont, E. (2016). Gender justice v. the 'invisible hand' of gender bias in law and society. Hypatia, 31(3), 668686.

Berg Gundersen, A. E., Sørlie, T., \& Bergvik, S. (2016). Women with coronary heart disease: Making sense of their symptoms and their experiences from interacting with their general practitioners. Health Psychology \& Behavioral Medicine, 5(1), 29-40.

Bleakley, A. (2013). Gender matters in medical education. Medical Education, 47(1), 59-70. https://www.ncbi. nlm.nih.gov/pubmed/23278826.

Briones-Vozmediano, E. (2017). The social construction of fibromyalgia as a health problem from the perspective of policies, professionals, and patients. Global Health Action, 10(1), 1275191. https://www.ncbi.nlm.nih.gov/ pubmed/28333581.

Britto, J. (2018). Diagnostic error and diagnostic decision support. Technology \& Clinical Support, 50(2), 42-45.

Celik, H., Lagro-Janssen, T. A., Widdershoven, G. G., \& Abma, T. A. (2011, Aug). Bringing gender sensitivity into healthcare practice: A systematic review. Patient Education \& Counselling, 84(2), 143-149. https://www. ncbi.nlm.nih.gov/pubmed/20719461.

Ceplak, M. M., \& Hlebec, V. (2012). Trust in an individual physican and its contradictions. Zdrav Var, 51, 53-68.

Chapman, E., Kaatz, A., \& Carnes, M. (2013, Nov). Physicians and implicit bias: How doctors may unwittingly

perpetuate health care disparities. Journal of General Internal Medicine, 28(11), 1504-1510. https://www. ncbi.nlm.nih.gov/pubmed/23576243.

Chapman, K., Tashkin, D., \& Pye, D. (2001). Gender bias in the diagnosis of COPD. Chest, 119(6), 1691-1695.

Chen, L., \& Standing, H. (2007). Gender equity in transitional China's healthcare policy reforms. Feminist Economics, 13(3-4), 189-212.

Colyar, J. E. (2012). Dialogues of contradiction: Low-income students and the transition to college. Metropolitan Universities, 22(3), 83-97.

Davidson, P. M., Mitchell, J. A., DiGiacomo, M., Inglis, S., Newton, P. J., Harman, J., \& Daly, J. (2012). Cardiovascular disease in women: Implications for improving health outcomes. Collegian, 19(1), 5-13.

Delgado, A., Saletti-Cuesta, L., Lopez-Fernandez, L. A., Gil-Garrido, N., \& de Dios Luna Del Castillo, J. (2016). Gender inequalities in COPD decision-making in primary care. Respiratory Medicine, 114, 91-96. https://doi. org/10.1016/j.rmed.2016.03.017.

Department of Health and Social Care. (2013). Cardiovascular disease outcomes strategy: Improving outcomes for people with or at risk of cardiovascular disease. https://www.gov.uk/government/publications/cardiovasculardisease-outcomes-strategy-improving-outcomes-for-people-with-or-at-risk-of-cardiovascular-disease.

Donskoy, A.-L. (2015). Coercion and trust in psychiatry: The ultimate contradiction. International Journal of Human Rights in Healthcare, 8(2), 70-81.

Dowding, D., Lichtner, V., Allcock, N., Briggs, M., James, K., Keady, J., Lasrado, R., Sampson, E., Swarbrick, C., \& Closs, S. (2016). Using sense-making theory to aid understanding of the recognition, assessment and management of pain in patients with dementia in acute hospital settings. International Journal of Nursing Studies, 53, 152-162.

Farmer, P. (2004). An anthropology of structural violence. Current Anthropology, 45(3), 305-325. https://doi.org/10.1086/382250.

Fish, J. (2009). Our health, our say: Towards a feminist perspective of lesbian health psychology. Feminism \& Psychology, 19(4), 437-453. 
FitzGerald, C., \& Hurst, S. (2017). Implicit bias in healthcare professionals: A systematic review. BMC Medical Ethics, 18(1), 19. https://www.ncbi.nlm.nih.gov/pubmed/28249596.

Gerolamo, A. M., Jutel, A., Kovals, D., Gentsch, A., Doty, A., \& Rising, K. (2018). Patient-identified needs related to seeking a diagnosis in the emergency department. Annals of Emergency Medicine, 72(3), 282-288. https://doi.org/10.1016/j.annemergmed.2018.02.021.

Graber, M. L., Franklin, N., \& Gordon, R. (2005). Diagnostic error in internal medicine. Archive of Internal Medicine, 165, 1493-1499.

Hagan, T. L., Rosenzweig, M. Q., Zorn, K. K., van Londen, J., \& Donovan, H. S. (2017). Perspectives on selfadvocacy: Comparing perceived uses, benefits and drawbacks among survivors and providers. Oncology Nursing Forum, 44(1), 52-59.

Hagel, J., Brown, J. S., Samoylova, T., \& Arkenberg, C. (2013). Coherency in contradiction. https://www2. deloitte.com/insights/us/en/industry/technology/coherency-in-contradictions.html.

Hamberg, K., Risberg, G., Johansson, E., \& Westman, G. (2002). Gender bias in physicians' management of neck pain: A study of the answers in a Swedish national examination. Journal of Women's Health, 11(7),653-666.

Hare-Mustin, R., \& Marecek, J. (1998). The meaning of difference: Gender theory, postmodernism, and psychology. American Psychologist, 43(6), 455-464.

Harrington, C. (2017). Meaning making in wartime bereavement: Lessons learned from bereaved parents and siblings. Journal of Death and Dying, 76(2), 103-121.

Holmes, S. (2016). 'Blindness to the obvious'? Treatment experiences and feminist approaches to eating disorders. Feminism \& Psychology, 26(4), 464-486.

Houkamau, C. A., Stronge, S., \& Sibley, C. G. (2017). The prevalence and impact of racism toward indigenous Maori in New Zealand. International Perspectives in Psychology: Research, Practice, Consultation, 6(2), 6180. https://doi.org/http://dx.doi.org/10.1037/ipp0000070.

Joseph-Williams, N., Elwyn, G., \& Edwards, A. (2014). Knowledge is not power for patients: A systematic review and thematic synthesis of patient-reported barriers and facilitators to shared decision making. Patient Education Counselling, 94(3), 291-309.

Jutel, A. (2019). 'The expertness of his healer': Diagnosis, disclosure and the power of a profession. Health, 23(3), 289-305. https://doi.org/10.1177/1363459317745956.

Jutel, A. G., \& Dew, K. (2015). Social issues in diagnosis: An introduction for clinicians and students. John Hopkins University Press. https://doi.org/doi/full/10.1111/1467-9566.12252.

Katz, J. D., Seaman, R., \& Diamond, S. (2008). Exposing gender bias in medical taxonomy: Toward embracing a gender difference without disenfranchising women. Women's Health Issues, 18(3), 151-154. https://www.ncbi. nlm.nih.gov/pubmed/18457752.

Kim, J.-H. (2016). Narrative data analysis and interpretation: 'Flirting' with data. In Understanding narrative inquiry. The crafting and analysis of stories as research (pp. 185-224). Sage.

Koyama, A., Ohtake, Y., Yasuda, K., Sakai, K., Sakamoto, R., Matsuoka, H., Okumi, H., \& Yasuda, T. (2018). Avoiding diagnostic errors in psychosomatic medicine: A case series study. Biopsychosocial Medicine, 12, 4. https://www.ncbi.nlm.nih.gov/pubmed/29563965.

Latz, M. (1994). Medical family therapy casebook at the heart of the matter: One woman's bypass experience. Family Systems Medicine 12, 205-211.

Levin, M., Mor, M., \& Ben-Hur, T. (2003). Patterns of misdiagnosis of multiple sclerosis. Israel Medical Association Journal, 5, 489-490.

Lorentzen, J. (2008). 'I know my own body': Power and resistance in women's experiences of medical interactions. Body \& Society, 14(3), 49-79.

Lyons, A., \& Chamberlain, K. (2013). Health psychology: A critical introduction. Cambridge University Press.

Marcum, J. A. (2015). Clinical decision-making, gender bias, virtue epistemology, and quality healthcare. Topoi, 36(3), 501-508.

Maserejian, N. N., Link, C. L., Lutfey, K. L., Marceau, L. D., \& McKinlay, J. B. (2009). Disparities in physicians' interpretations of heart disease symptoms by patient gender: Results of a video vignette factorial experiment. Journal of Women's Health, 18(10), 1661-1667.

McSweeney, J. C., Lefler, L. L., \& Crowder, B. F. (2005). What's wrong with me? Women's coronary heart disease diagnostic experiences. Progress in Cardiovascular Nursing 20, 48-57.

Ministry of Health. (2002). Reducing inequalities in health. https://www.health.govt.nz/publication/reducinginequalities-health.

Munch, S. (2004). Gender-biased diagnosing of women's medical complaints: Contributions of feminist thought, 1970-1995. Women's Health, 40(1), 101-121. https://www.ncbi.nlm.nih.gov/pubmed/15778134. 
Neale, G., Hogan, H., \& Sevdalis, N. (2011). Misdiagnosis: Analysis based on case record review with proposals aimed to improve diagnostic processes. Clinical Medicine, 11(4), 317-321.

Newman-Toker, D., Moy, E., Valente, E., Coffey, R., \& Hines, A. (2014). Missed diagnosis of stroke in the emergency department: A sectional analysis of a large population-based sample. Diagnosis (Berlin), 1(2), 155166.

Nicolson, P. (2004). Biological politics: Challenging man-made science. Feminism \& Psychology, 14(3), 411-414.

Parker, R., Larkin, T., \& Cockburn, J. (2017). A visual analysis of gender bias in contemporary anatomy textbooks. Social Science Medicine, 180, 106-113. https://www.ncbi.nlm.nih.gov/pubmed/28343109.

Payne, S., \& Doyal, L. (2010). Gender equity or gender equality in health? Policy \& Politics, 38(1), 171-175.

Pelaccia, T., Messmand, A., \& Kline, J. (2020). Misdiagnosis and failure to diagnose in emergency care: Causes and empathy as a solution. Patient Education \& Counselling, 103, 1650-1656.

Reid, P., Cormack, D., \& Paine, S.-J. (2019). Colonial histories, racism and health: The experience of Māori and indigenous peoples. Public Health, 172, 119-124. https://doi.org/10.1016/j.puhe.2019.03.027.

Rickard, D. (2015). Masculinity and medicalization: Gender and vocabularies of motive in the narrative of a sex offender. Feminism \& Psychology, 25(2), 199-218.

Risberg, G., Johansson, E. E., \& Hamberg, K. (2011). 'Important ... but of low status': Male education leaders' views on gender in medicine. Medical Education, 45(6), 613-624. https:/www.ncbi.nlm.nih.gov/ pubmed/21564199.

Ross, P. T., \& Lypson, M. L. (2014). Using artistic-narrative to stimulate reflection on physician bias. Teaching \& Learning Medicine, 26(4), 344-349. https://www.ncbi.nlm.nih.gov/pubmed/25318028.

Ruggiano, N., Whiteman, K., \& Shtompel, N. (2014). 'If I don't like the way I feel with a certain drug, I'll tell them.' Older adults' experiences with self-determination and health self-adovcacy. Journal of Applied Gerontology, 35(4), 401-420.

Saletti-Cuesta, L., Tutton, L., \& Wright, J. (2016). The relevance of gender in the care of hip fracture patients. International Journal of Orthopedic Trauma Nursing, 22, 3-12. https:/www.ncbi.nlm.nih.gov/ pubmed/27215748.

Sanfey, H. (2005). Gender-specific issues in liver and kidney failure and transplantation: A review. Journal of Women's Health, 14(7), 617-626.

Smirthwaite, G., \& Swahnberg, K. (2016). Comparing critical realism and the situated knowledges approach in research on (in)equity in health care: An exploration of their implications. Journal of Critical Realism, 15(5), 476-493.

Smythe, L. (2012). Discerning which qualitative approach fits best. New Zealand College of Midwives, 46, 5-12.

Squire, C., Andrews, M., \& Tamboukou, M. (2013). Introduction: What is narrative research. In M. Andrews, C. Squire, \& M. Tamboukou (Eds.), Doing narrative research (pp. 1-26). Sage.

Teunissen, T. A. M., Rotink, M. E., \& Lagro-Janssen, A. L. M. (2016). Gender differences in quality of care experiences during hospital stay: A contribution to patient-centered healthcare for both men and women. Patient Education \& Counselling, 99(4), 631-637. https://www.ncbi.nlm.nih.gov/pubmed/26590706.

University of Leeds. (2016). Heart attacks in women more likely to be missed. https://www.leeds.ac.uk/news/ article/3905/heart_attacks_in_women_more_likely_to_be_missed.

Ussher, J. (2004). Biological politics revisited: Reclaiming the body and the intra-psychic within discursive feminist psychology. Feminism \& Psychology, 14(3), 425-430.

Ussher, J. (2013). Diagnosing difficult women and pathologising femininity: Gender bias in psychiatric nosology. Feminism \& Psychology, 23(1), 63-69.

Valenti, C. M. (2011). A new look at survivorship: Female cancer survivors' experience of resilience in the face of adversity. (Doctoral thesis, Wright State University, Dayton, Ohio). https://corescholar.libraries.wright.edu/etd_all/1121/.

Verdonk, P., Benschop, Y., de Haes, H., \& Lagro-Janssen, T. (2009). From gender bias to gender awareness in medical education. Advanced Health Science, Education \& Theory Practice, 14(1), 135-152. https://www. ncbi.nlm.nih.gov/pubmed/18274877.

Waldron, N., Brown, S. J., Hewlett, S., Elliott, B., McHugh, N., \& McCabe, C. S. (2012). 'To suddenly have a name for this thing ... was wonderful': The patient's experience of receiving a diagnosis of systemic lupus erythematosus. Musculoskeletal Care, 10(3), 135-141. https://www.ncbi.nlm.nih.gov/pubmed/22514146.

Walsh, I., Holton, J. A., Fernandez, W., Levina, N., \& Glaser, B. (2015). What grounded theory is ... A critically reflective conversation among scholars. Organisational Research Methods, 18(4), 581-599. 
Wehbe-Alamah, H., Kornblau, B. L., Haderer, J., \& Erickson, J. (2012). Silent no more! The lived experiences of women with lichen sclerosis. Journal of American Academic Nurse Practice, 24(8), 499-505. https://www. ncbi.nlm.nih.gov/pubmed/22845033.

Weigert, K. M. (2008). Structural violence. In L. Kurtz (Ed.), Encyclopedia of violence, peace, and conflict (pp. 2004-2011). 2nd ed. Elsevier Inc. https://doi.org/10.1016/B978-012373985-8.00169-0.

Wenger, N. (2004). You've come a long way, baby: Cardiovascular health and disease in women - problems and prospects. Circulation, 109, 558-560.

Wienclaw, R. (2013). Health and medicine: Feminist perspectives. In Research starters: Sociology. Ispwich, MA: EBSCO Publishing.

Wiklund, M., Fjellman-Wiklund, A., Stalnacke, B. M., Hammarstrom, A., \& Lehti, A. (2016). Access to rehabilitation: Patient perceptions of inequalities in access to specialty pain rehabilitation from a gender and intersectional perspective. Global Health Action, 9. https://www.ncbi.nlm.nih.gov/pubmed/27569592.

Wiltshire, J., Cronin, K., Sarto, G., \& Brown, R. (2006). Self-sdvocacy during the medical encounter: Use of health information and racial/ethnic differences. Medical Care, 44(2), 100-109.

Women's Health Action. (2020). Heart disease. https://womens-health.org.nz/health-topics/heart-disease/.

Worrall-Carter, L., Ski, C., Scruth, E., Campbell, M., \& Page, K. (2011). Systematic review of cardiovascular disease in women: Assessing the risk. Nursing \& Health Sciences, 13(4), 529-35.

Wright, P., McCarthy, J., \& Meekison, L. (2004). Making sense of experience. In M. Blythe, A. Monk, K. Overbeek, \& P. Wright (Eds.) Funology (pp. 43-53). Kluwer Academic. 